\title{
Article \\ Sparsomycin Exhibits Potent Antiplasmodial Activity In Vitro and In Vivo
}

\author{
Nanang Rudianto Ariefta ${ }^{1}\left(\mathbb{D}\right.$, Baldorj Pagmadulam ${ }^{1,2}$, Coh-ichi Nihei ${ }^{3}$ and Yoshifumi Nishikawa ${ }^{1, *(\mathbb{D})}$ \\ 1 National Research Center for Protozoan Diseases, Obihiro University of Agriculture and Veterinary Medicine, \\ Inada-cho, Obihiro 080-8555, Japan; nanang.ariefta@gmail.com (N.R.A.); pagmadulam1028@gmail.com (B.P.) \\ 2 Laboratory of Microbial Synthesis, Institute of General and Experimental Biology, Mongolian Academy of \\ Sciences, Ulaanbaatar Peace Avenue-54b, Ulaanbaatar 13330, Mongolia \\ 3 Institute of Microbial Chemistry (BIKAKEN), 3-14-23 Kamiosaki, Shinagawa-ku, Tokyo 141-0021, Japan; \\ conihei@bikaken.or.jp \\ * Correspondence: nisikawa@obihiro.ac.jp
}

check for updates

Citation: Ariefta, N.R.; Pagmadulam, B.; Nihei, C.-i.; Nishikawa, Y. Sparsomycin Exhibits Potent Antiplasmodial Activity In Vitro and In Vivo. Pharmaceutics 2022, 14, 544. https://doi.org/10.3390/ pharmaceutics14030544

Academic Editor: Bruno Sarmento

Received: 1 February 2022

Accepted: 26 February 2022

Published: 28 February 2022

Publisher's Note: MDPI stays neutral with regard to jurisdictional claims in published maps and institutional affiliations.

Copyright: (c) 2022 by the authors. Licensee MDPI, Basel, Switzerland. This article is an open access article distributed under the terms and conditions of the Creative Commons Attribution (CC BY) license (https:// creativecommons.org/licenses/by/ $4.0 /)$.

\begin{abstract}
The emerging spread of drug-resistant malaria parasites highlights the need for new antimalarial agents. This study evaluated the growth-inhibitory effects of sparsomycin (Sm), a peptidyl transferase inhibitor, against Plasmodium falciparum 3D7 (chloroquine-sensitive strain), P. falciparum K1 (resistant to multiple drugs, including chloroquine), P. yoelii 17XNL (cause of uncomplicated rodent malaria) and P. berghei ANKA (cause of complicated rodent malaria). Using a fluorescence-based assay, we found that Sm exhibited half-maximal inhibitory concentrations $\left(\mathrm{IC}_{50}\right)$ of 12.07 and $25.43 \mathrm{nM}$ against $P$. falciparum 3D7 and K1, respectively. In vitro treatment of $P$. falciparum 3D7 with Sm at 10 or $50 \mathrm{nM}$ induced morphological alteration, blocked parasites in the ring state and prevented erythrocyte reinvasion, even after removal of the compound. In mice infected with $P$. yoelii 17XNL, the administration of $100 \mu \mathrm{g} / \mathrm{kg}$ Sm for 7 days did not affect parasitemia. Meanwhile, treatment with $300 \mu \mathrm{g} / \mathrm{kg}$ Sm resulted in a significantly lower parasitemia peak (18.85\%) than that observed in the control group (40.13\%). In mice infected with P. berghei ANKA, both four and seven doses of $\mathrm{Sm}(300 \mu \mathrm{g} / \mathrm{kg})$ prolonged survival by $33.33 \%$. Our results indicate that $\mathrm{Sm}$ has potential antiplasmodial activities in vitro and in vivo, warranting its further development as an alternative treatment for malaria.
\end{abstract}

Keywords: sparsomycin; antiplasmodial; Plasmodium falciparum; Plasmodium yoelii; Plasmodium berghei

\section{Introduction}

Malaria is a mosquito-borne infectious disease caused by protozoan parasites of the genus Plasmodium. Approximately half of the global population is at risk for the disease, especially socio-economically disadvantaged populations [1]. Based on the World Malaria Report 2021, an estimated 241 million malaria cases occurred globally in 2020, up from 227 million in 2019, with most of this increase arising from countries in the African region. Conversely, malaria deaths increased by $12 \%$ versus 2019 to an estimated 627,000. The increase in 2020 was associated with the disruption of malaria prevention, diagnosis and treatment during the COVID-19 pandemic [2].

One of the threats to efforts to eradicate malaria is the emergence of drug-resistant parasites [3]. For example, chloroquine-resistant $P$. falciparum and P. vivax spread from 1957 to 1987 through Asia, South America and Africa and, more recently, P. falciparum resistant to artemisinin derivatives was identified in Southeast Asia, leading to significant rates of treatment failure for these gold-standard combination therapies [4]. The spread of multidrug-resistant malaria parasites is broadly caused by four factors, i.e., mutation and/or amplification of the target(s), stress response-based survival mechanisms and removal or sequestration of drugs and detoxifications [5]. Thus, the continuous development of novel antimalarial compounds is needed. Accordingly, we screened a compound 
library consisting of natural products and natural-product derivatives, curated by the Institute of Microbial Chemistry. From this screening, sparsomycin was stood out to exhibit antiplasmodial activity at the nanomolar scale and was further evaluated in this study.

Sparsomycin $(\mathrm{Sm})$ is an antibiotic that was initially isolated from Streptomyces sparsogenes in 1962 [6]. Its structure contains a rare monoxodithioacetal moiety (Figure 1). Sm acts as a protein biosynthesis inhibitor in bacteria, archaea and eukaryotes and it selectively acts on several human tumors [7]. Sm interferes with peptide bond formation, a process that is essential to protein biosynthesis, on the large ribosomal subunit (50S and 60S) [8]. Sm binds primarily to the peptidyl (P) site and, because of the stabilization of the P-site/tRNA, the drug blocks the critical movement of tRNAs between the aminoacyl site and P-site, resulting in the inhibition of peptide bond formation and the inability of aminoacyl-tRNA to access the P-site [9-11]. Despite acute toxicity of Sm in mice [6] and Sm-related retinopathy in the phase I clinical study [12], an active testing program of the drug related to the protein biosynthesis machinery has continued $[10,13,14]$. Considering the effects of Sm on protein translation, the in vitro inhibitory activity of $\mathrm{Sm}$ against the most common and deadliest human malaria parasite, P. falciparum (3D7 and K1) [15], was evaluated. P. falciparum 3D7 represents a chloroquine-sensitive strain and P. falciparum $\mathrm{K} 1$ represents a multi-drug resistant strain, including chloroquine, sulphadoxine, pyrimethamine and cycloguanil [16]. Furthermore, to confirm the in vitro results, the effects of Sm were also evaluated in vivo using two rodent malaria parasites with different virulence characteristics, P. yoelii 17XNL and P. berghei ANKA, respectively, for uncomplicated/non-lethal and complicated/lethal strains [17].<smiles>CSCS(=O)C[C@H](CO)NC(=O)/C=C/c1c(C)[nH]c(=O)[nH]c1=O</smiles>

Figure 1. The structure of sparsomycin.

\section{Materials and Methods}

\subsection{Compounds}

Sm (molecular weight (MW), $361.43 \mathrm{~g} / \mathrm{mol}$; CAS 1404-64-4, Cat. No. 29934) was purchased from Cayman Chemical (Ann Arbor, MI, USA). Chloroquine diphosphate (MW, 515.86 g/mol; CAS 50-63-5, Cat. No. C6628) and artemisinin (MW, 282.33 g/mol; CAS 63968-64-9, Cat. No. 361593) were purchased from Sigma-Aldrich (St. Louis, MO, USA). Stock solutions were prepared in MilliQ water for Sm $(2.8 \mathrm{mM})$ and chloroquine diphosphate $(20 \mathrm{mM})$ and in $100 \%$ DMSO for artemisinin $(20 \mathrm{mM})$. The stocks were stored at $-30{ }^{\circ} \mathrm{C}$ until use and diluted as required.

\subsection{Parasites}

This study used two strains of P. falciparum for in vitro analyses, namely, chloroquinesensitive (3D7) and multidrug-resistant (K1) strains, obtained from Dr. Shin-ichiro Kawazu (National Research Center for Protozoan Diseases, Obihiro University of Agriculture and Veterinary Medicine, Japan). Two rodent malaria parasites were used for in vivo studies, namely, P. yoelii 17XNL (for uncomplicated rodent malaria) and P. berghei ANKA (for complicated rodent malaria), obtained from the Department of Molecular Parasitology, Ehime University Graduate School of Medicine, Japan.

\subsection{In Vitro Culture of P. falciparum}

P. falciparum strains 3D7 and K1 were cultivated in 2\% washed human O-positive erythrocytes (supplied by Japanese Red Cross Society, Hokkaido, Japan) using a multi-gas 
incubator $\left(37{ }^{\circ} \mathrm{C}, 5 \% \mathrm{CO}_{2}\right.$ and $\left.5 \% \mathrm{O}_{2}\right)$. Roswell Park Memorial Institute (RPMI)-1640 medium (Cat. No. R6504, Sigma-Aldrich, St. Louis, MO, USA) containing 25 mM HEPES (CAS 7365-45-9, Cat. No. H4034; Sigma-Aldrich, St. Louis, MO, USA), $184 \mu$ M hypoxanthine (CAS 68-94-0, Cat. No. 086-03403; Wako, Osaka, Japan), 24 mM NaHCO (CAS $^{-1}$ 144-55-8, Cat. No. 198-01215; Wako, Osaka, Japan), 0.025\% (v/v) gentamicin (50 mg/mL; CAS 1403-66-3, Cat. No. 15750078; Gibco, Waltham, MA, USA) and 0.5\% (w/v) AlbuMax ${ }^{\mathrm{TM}}$ II Lipid-Rich BSA (Cat. No. 11021029; Gibco, Waltham, MA, USA), designated as complete medium, was used for the parasite culture. Parasitemia was monitored using Giemsastained thin blood smears (CAS 51811-82-6, Cat. No. 48900; Merck, Darmstadt, Hesse, Germany); the medium was changed daily and subculturing was performed as required.

\subsection{In Vitro Inhibition Assay of P. falciparum}

The in vitro growth inhibition of P. falciparum 3D7 and K1 was examined using the SYBR Green I-based fluorescence assay $\left(S_{Y B R}{ }^{\circledR}\right.$ Green I Nucleic Acid Stain 10,000× ; Cat. No. 50513; Lonza, Basel, Switzerland) as previously described [18,19]. Briefly, test compounds were diluted in complete medium to eight desired concentrations (2-fold serial dilution). Next, the parasites were synchronized using treatment of 5\% D-sorbitol (CAS 50-70-4, Cat. No. 191-14735; Wako, Osaka, Japan) to obtain $\geq 90 \%$ ring-stage parasites. Next, $50 \mu \mathrm{L}$ of synchronous parasites at $0.5 \%$ parasitemia and $2 \%$ hematocrit was seeded in a 96 -well plate containing $50 \mu \mathrm{L}$ of test compounds. The 96-well plate was incubated for $72 \mathrm{~h}$ at $37{ }^{\circ} \mathrm{C}, 5 \% \mathrm{CO}_{2}$ and $5 \% \mathrm{O}_{2}$. Next, $100 \mu \mathrm{L}$ of lysis buffer containing $0.02 \%(v / v)$ SYBR Green I was added to each well and mixed and then the 96-well plate was incubated at room temperature for $2 \mathrm{~h}$ in the dark. The fluorescence intensities were then measured using a Fluoroskan Ascent instrument (Thermo Fisher Scientific, Waltham, MA, USA) at excitation and emission wavelengths of 485 and $518 \mathrm{~nm}$, respectively. Erythrocytes treated with 1\% DMSO were used as a negative control and wells containing only test compounds and erythrocytes were used to correct background signals. In at least three independent trials, the inhibition assay was performed in quadruplicate for each concentration.

\subsection{Microscopic Analysis of Parasitemia and Morphology of P. falciparum 3D7 Treated with Sm In Vitro}

The parasites were tightly synchronized using a two-step sorbitol treatment protocol [20] and used at the ring stage with $0.5 \%$ parasitemia and $2 \%$ hematocrit. Sm (50 and $10 \mathrm{nM}$ ) in complete medium and 1\% DMSO in complete medium were used as the treated and untreated groups, respectively, in this assay. Subsequently, the Giemsastained thin blood smears of each treatment group were prepared after 1, 24, 48, or $72 \mathrm{~h}$ of incubation. After $72 \mathrm{~h}$, incubation was continued after changing the medium in either the presence (unwashed group) or absence (washed group) of Sm for up to $144 \mathrm{~h}$. Subsequently, the Giemsa-stained thin blood smears of each treatment group were prepared at 96, 120 and $144 \mathrm{~h}$. The blood smears were observed using a BZ-900 all-in-one microscope (Keyence BioRevo, Tokyo, Japan). The parasitemia levels were determined by enumerating the number of infected erythrocytes in relation to uninfected erythrocytes (a minimum of 500 cells were counted). The assay was performed in triplicate for each concentration and time point.

\subsection{In Vitro Cytotoxicity in Human Cells}

Cultures of human foreskin fibroblasts (HFFs) were maintained in Dulbecco's modified Eagle medium (DMEM; Cat. No. D0819; Sigma, St. Louis, MO, USA) supplemented with 10\% fetal bovine serum (FBS; Cat. No. S181A; Biowest, Riverside, MO, USA) and 1\% penicillin-streptomycin solution ( $\times 100$; Cat. No. 168-23191; Wako, Osaka, Japan) at $37^{\circ} \mathrm{C}$ and $5 \% \mathrm{CO}_{2}$. A cell viability assay was used to evaluate the cytotoxic action of $\mathrm{Sm}$ as described previously [18]. Briefly, a $100 \mu \mathrm{L}$ cell suspension was seeded in a 96-well plate at a concentration of $1 \times 10^{5}$ cells $/ \mathrm{mL}$ in DMEM containing 10\% FBS and incubated for $48 \mathrm{~h}$ at $37{ }^{\circ} \mathrm{C}$ and $5 \% \mathrm{CO}_{2}$. Next, 2-fold dilutions (total of eight concentrations) of test 
compounds in DMEM were added in quadruplicate to each well and incubated for an additional 72 h. After that, a Cell Counting Kit-8 (CCK-8; Cat. No. 343-07623; Dojindo, Kumamoto, Japan) was added, cells were incubated for an additional $3 \mathrm{~h}$ at $37{ }^{\circ} \mathrm{C}$ and $5 \%$ $\mathrm{CO}_{2}$ and the absorbance was measured at $450 \mathrm{~nm}$.

\subsection{In Vitro Sm Hemolysis Rate in Human Erythrocytes}

An erythrocyte hemolysis assay was performed as previously described [21]. Briefly, $100 \mu \mathrm{L}$ of each compound (final concentration, $100 \mu \mathrm{M}$ ) in $1 \times$ phosphate-buffered saline (PBS) was seeded in a 96-well plate and $100 \mu \mathrm{L}$ of a 3\% erythrocyte suspension in PBS was added. The plate was incubated for $3 \mathrm{~h}$ at $37^{\circ} \mathrm{C}, 5 \% \mathrm{CO}_{2}$ and $5 \% \mathrm{O}_{2}$ and then centrifuged at $1300 \times g$ for $5 \mathrm{~min}$. Subsequently, $100 \mu \mathrm{L}$ of the supernatant of each mixture was transferred to a new 96-well plate and the absorbance was recorded at $540 \mathrm{~nm}$. PBS (containing 1\% DMSO) and erythrocyte lysis buffer $\left(0.83 \% \mathrm{NH}_{4} \mathrm{Cl} ; 0.01 \mathrm{M}\right.$ Tris- $\left.\mathrm{HCl}, \mathrm{pH} 7.2\right)$ served as the negative and positive controls, respectively. The erythrocyte hemolysis rate was calculated using the following formula: hemolysis rate $=\left(\left[\mathrm{A}_{\text {sample }}-\mathrm{A}_{\text {negative control }}\right] /\left[\mathrm{A}_{\text {positive control }}-\mathrm{A}_{\text {negative control }}\right] \times 100\right)$, where $\mathrm{A}$ is absorbance [21]. The experiments were performed in triplicate and repeated three times independently.

\subsection{Mice and In Vivo Infections}

Male C57BL/6 J mice (8 weeks old with body weight of 20-25 g; six mice per group) were purchased from Japan CLEA (Tokyo, Japan). The mice were allowed free access to water and food (CLEA Rodent Diet CE-2; Japan CLEA, Tokyo, Japan). The room temperature $\left(24^{\circ} \mathrm{C}\right)$, relative humidity (50\%) and lighting (light from 8 a.m. to 8 p.m.) were adjusted and controlled. P. yoelii 17XNL and P. berghei ANKA were recovered from frozen packed erythrocyte stocks via passage in mice following intraperitoneal (i.p.) injection. Challenge experiments were performed with i.p. injections of $1 \times 10^{7}$ fresh infected erythrocytes from donor mice (designated as 0 days post-infection (dpi)). Approximately $2 \mathrm{~h}$ after the injection, $2 \mu \mathrm{L}$ of blood was collected from the tip of the mice's tail and the parasitemia levels were checked using Giemsa-stained thin blood smears. When the parasitemia level reached $1 \%$, the infected mice were intraperitoneally treated with vehicle $\left(1 \times\right.$ PBS) or Sm at a dose of 100 or $300 \mu \mathrm{g} / \mathrm{kg}$ (modified from reported IC $_{50}$ in Ref. [22]) once daily for 7 days (0-6 dpi; modified Peters' test [23]) for P. yoelii 17XNL and $300 \mu \mathrm{g} / \mathrm{kg}$ once daily for 4 (0-3 dpi; Peters' 4-day test [24]) or 7 days (0-6 dpi, [23]) for P. berghei ANKA. The survival and clinical signs of mice were monitored daily after infection. Mice with high clinical signs (arched back, immobility, >20\% body weight loss and pain sign) were euthanized immediately. Parasitemia in P. yoelii 17XNL-infected mice was observed daily using Giemsa-stained thin blood smears (up to $30 \mathrm{dpi}$ ).

\subsection{Statistical Analysis}

Data were analyzed using GraphPad Prism 8 (GraphPad Software, Inc., La Jolla, CA, USA). $\mathrm{IC}_{50}$ or $\mathrm{CC}_{50}$ values were calculated from three independent experiments using a nonlinear regression fit to logarithm concentration value of the compound versus inhibition percentage of parasite or cell growth, respectively. Group comparison analyses were performed using the one-way or two-way ANOVA followed by Tukey's or Sidak's multiple comparison test. Survival rates were calculated using the log-rank (Mantel-Cox) test. A $p$-value of $<0.05$ was considered statistically significant and is shown as an asterisk or a symbol, defined in each table/figure legend together with the name of the test used.

\section{Results}

\subsection{Effects of Sm on P. falciparum In Vitro}

The antiplasmodial activity of Sm in vitro versus artemisinin and chloroquine was determined using P. falciparum 3D7 and K1. As presented in Table 1, Sm inhibited the growth of both $P$. falciparum 3D7 and $\mathrm{K} 1$ with $\mathrm{IC}_{50}$ values of $12.07 \pm 4.41$ and $25.43 \pm 8.15 \mathrm{nM}$, respectively. The cytotoxicity of Sm against HFFs was confirmed with a $\mathrm{CC}_{50}$ of $1.14 \pm 0.03 \mu \mathrm{M}$, 
resulting in selectivity indices (SIs) of 94.45 (3D7) and 44.83 (K1). Furthermore, at a concentration of $100 \mu \mathrm{M}, \mathrm{Sm}$ induced an erythrocyte hemolysis rate of $1.04 \pm 0.23 \%$.

Table 1. Summary of the in vitro activities of sparsomycin compared with the positive controls *.

\begin{tabular}{|c|c|c|c|c|c|c|c|}
\hline \multirow[t]{2}{*}{ Compound } & \multicolumn{2}{|c|}{$\begin{array}{c}\mathrm{IC}_{50} \\
\text { P. falciparum (nM) }\end{array}$} & \multirow{2}{*}{$\begin{array}{l}\text { Resistance } \\
\text { Index }\end{array}$} & \multirow{2}{*}{$\begin{array}{l}\mathrm{CC}_{50} \\
\mathrm{HFF} \\
(\mu \mathrm{M})\end{array}$} & \multicolumn{2}{|c|}{$\begin{array}{c}\text { SI for } \\
\text { P. falciparum }\end{array}$} & \multirow{2}{*}{$\begin{array}{c}\text { RBC Hemolysis } \\
\text { Rate (\%) } \\
\text { at } 100 \mu \mathrm{M}\end{array}$} \\
\hline & 3D7 & K1 & & & 3D7 & K1 & \\
\hline Sparsomycin & $12.07 \pm 4.41^{a}$ & $25.43 \pm 8.15^{a}$ & 2.1 & $1.14 \pm 0.03$ & 94.45 & 44.83 & $1.04 \pm 0.23$ \\
\hline Artemisinin & $13.18 \pm 2.66^{a}$ & $19.89 \pm 1.51^{a}$ & 1.4 & $\begin{array}{c}153.00 \pm \\
30.76\end{array}$ & $10,983.49$ & 7692.31 & $1.03 \pm 0.46$ \\
\hline Chloroquine & $26.20 \pm 3.66^{b}$ & $\begin{array}{c}740.07 \pm \\
95.67^{b}\end{array}$ & 28.24 & $20.71 \pm 6.80$ & 790.46 & 27.98 & $0.71 \pm 0.35$ \\
\hline
\end{tabular}

* Values are presented as the mean $\pm \mathrm{SD}$ of three independent experiments. $\mathrm{IC}_{50}$, half-maximal inhibitory concentration. $\mathrm{CC}_{50}$, half-maximal cytotoxic concentration. Resistance index, ratio between the $\mathrm{IC}_{50}$ values of P. falciparum $\mathrm{K} 1$ and $3 \mathrm{D} 7$. SI, selectivity index (ratio between $\mathrm{IC}_{50}$ and $\mathrm{CC}_{50}$ ). HFF, human foreskin fibroblast. RBC, red blood cell. The different letters $\left(a\right.$ or $b$ ) in the $\mathrm{IC}_{50}$ values indicate statistically significant differences among test compounds (one-way ANOVA followed by Tukey's multiple comparison test; $p<0.05$ ).

\subsection{Effects of Sm on parasitemia and the Morphology of P. falciparum 3D7 In Vitro}

A phenotype analysis of untreated and Sm-treated cultures of P. falciparum 3D7 was performed to investigate the parasitemia level and morphological changes under Sm exposure. Parasites were tightly synchronized using $5 \% D$-sorbitol to the ring stage and incubated with 0,10 , or $50 \mathrm{nM} \mathrm{Sm}$. Distinct differences were observed compared with the untreated group (Figure 2A). The life cycles of parasites were blocked in the ring stage over 1-72 h of incubation with 10 or $50 \mathrm{nM} \mathrm{Sm}$. Sm treatment at $50 \mathrm{nM}$ for $72 \mathrm{~h}$ induced morphological alterations, including shrinkage, as indicated by dot-like spots within erythrocytes. The parasitemia levels during this experiment were not increased along the incubation period (Figure 2B), indicating that reinvasion of the erythrocytes because of Sm underexposure did not occur. In cells cultured after $72 \mathrm{~h}$ of Sm exposure, the suppression of parasite growth continued in both the unwashed and washed groups and the parasites were continuously observed as shrunken dot-like spots within erythrocytes (Figure 3A). No increases in parasitemia levels were observed with prolonged incubation (Figure 3B).

\subsection{Effect of Sm on P. yoelii 17XNL-Infected Mice}

As presented in Figure $4 \mathrm{~A}, 100 \mu \mathrm{g} / \mathrm{kg} \mathrm{Sm}$ did not significantly alter parasitemia levels in P. yoelii 17XNL-infected mice versus the control. Meanwhile, $300 \mu \mathrm{g} / \mathrm{kg} \mathrm{Sm}$ significantly reduced parasitemia compared with the control throughout the observation period (Figure 4B). Furthermore, a significantly lower parasitemia peak (18.85\%) was observed in Sm-treated mice than in control mice (40.13\%). No mortality was observed in either control or Sm-treated mice. 


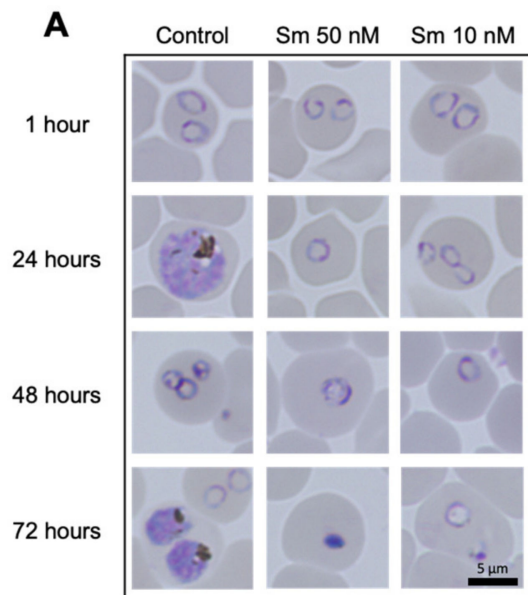

B

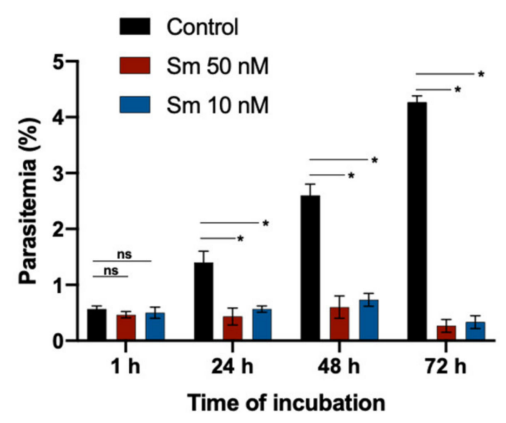

Figure 2. Representative morphology and parasitemia levels of parasites under no treatment (control) or sparsomycin (Sm) treatment (50 nM and $10 \mathrm{nM})$. (A) Parasite morphology after 1, 24, 48 and $72 \mathrm{~h}$ of incubation. The parasites in the treated group were retained in the ring stage, they were shrunken and they could not form trophozoites in the life cycle. Scale bar: $5 \mu \mathrm{m}$. (B) Parasitemia levels after 1, 24,48 and $72 \mathrm{~h}$ of incubation. Parasitemia levels are presented as the mean of triplicate wells and the error bars represent standard deviations. ${ }^{*}$, significant $(p<0.05)$; ns, not significant $(p>0.05)$. The significance of differences in the level of parasitemia of Sm-treated cultures compared with control were analyzed by two-way ANOVA and a Tukey's multiple comparison test.

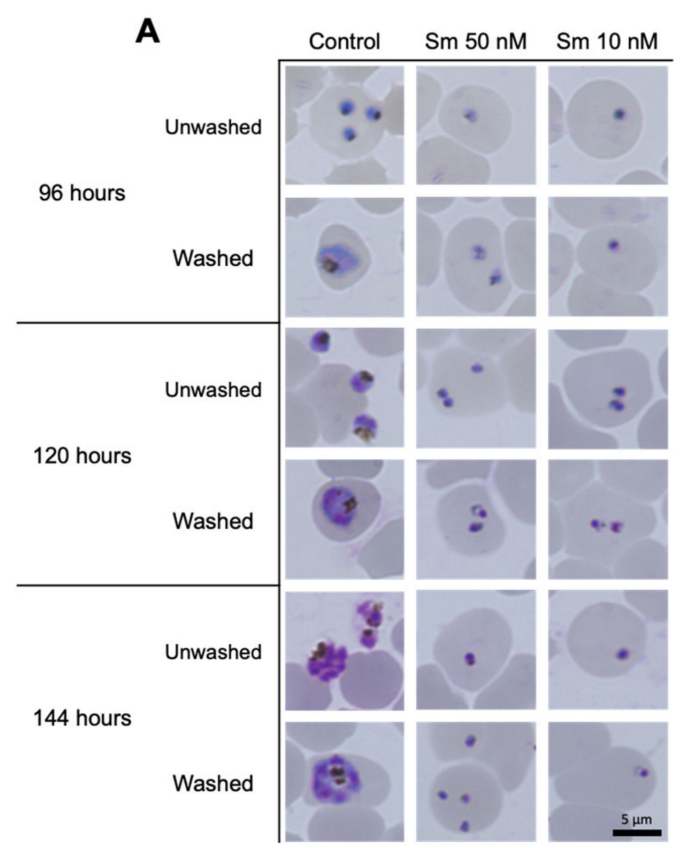

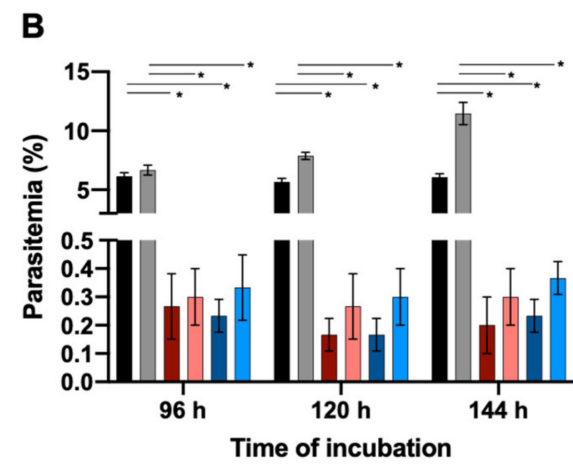

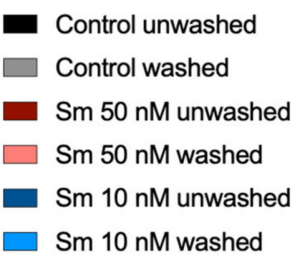

Figure 3. Representative morphologies and parasitemia levels of parasites after $72 \mathrm{~h}$ exposure of growth under no treatment (control) or sparsomycin $(\mathrm{Sm})$ treatment (50 and $10 \mathrm{nM})$. (A) Parasite morphologies after 96,120 and $144 \mathrm{~h}$ incubation in the presence (unwashed) or absence (washed) of $\mathrm{Sm}$. All parasites in the treated group were retained in the ring stage, they were shrunken and they could not form trophozoites in the life cycle. Scale bar: $5 \mu \mathrm{m}$. (B) Parasitemia levels after 96, 120 and $144 \mathrm{~h}$ of incubation in the presence (unwashed) or absence of Sm (washed). Parasitemia levels are presented as the mean of triplicate experiments and the error bars represent standard deviations. The significance of differences in the level of parasitemia of Sm-treated cultures compared with control were analyzed by two-way ANOVA and a Tukey's multiple comparison test ${ }^{*}$, significant at $\left.p<0.05\right)$. 
A

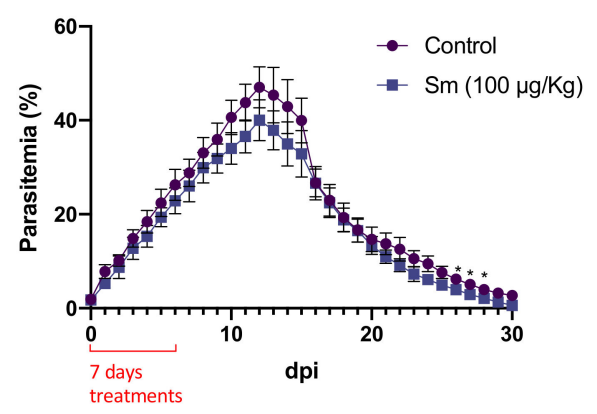

B

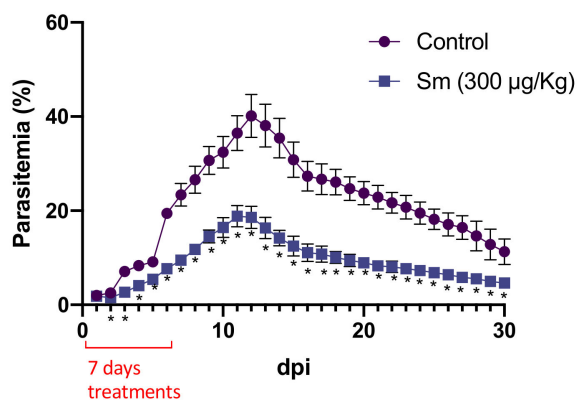

Figure 4. Effects of 7 days of sparsomycin (Sm) treatment on C57BL/6 mice infected with P. yoelii 17XNL. (A) Parasitemia levels after treatment with $100 \mu \mathrm{g} / \mathrm{kg} \mathrm{Sm}$ and (B) parasitemia levels after treatment with $300 \mu \mathrm{g} / \mathrm{kg}$ following the inoculation of $1 \times 10^{7}$ infected erythrocytes. Each group consisted of six mice. *: the significance of differences in the level of parasitemia in Sm-treated mice compared with control mice was analyzed by two-way ANOVA followed by Sidak's multiple comparison test $(p<0.05)$.

\subsection{Effect of Sm on P. berghei ANKA-Infected Mice}

On the basis of the effects of $300 \mu \mathrm{g} / \mathrm{kg}$ Sm on P. yoelii 17XNL-infected mice, the same dose was used in mice infected with $P$. berghei ANKA. Treatment for 4 or 7 days prolonged survival by $33.33 \%$ (up to $25 \mathrm{dpi}$ ). Although the effect of the 7 -day regimen was statistically insignificant $(p>0.05)$, the effects of this regimen on survival were generally in accordance with the effects of the 4-day regimen.

\section{Discussion}

Sm is a well-known peptidyl transferase inhibitor that acts by stabilizing the Psite within large ribosomal subunits and it has been demonstrated to stimulate factorindependent translocation [25]. In the case of cancerous cells, which are more sensitive to translation inhibitors than normal cells because of the hyperactivation of the translation machinery [26], the high uptake of the compound resulted in inhibited protein biosynthesis, thereby causing metabolic disorders, inhibiting cell proliferation and promoting cell death [27]. In this study, Sm inhibited the in vitro growth of P. falciparum 3D7 and $\mathrm{K} 1$ (Table 1) after $72 \mathrm{~h}$ of exposure with $\mathrm{IC}_{50}$ values of $12.07 \pm 4.41$ and $25.43 \pm 8.15 \mathrm{nM}$, respectively. The $\mathrm{IC}_{50}$ values were comparable to those of artemisinin $(13.18 \pm 2.66 \mathrm{nM}$ for 3D7 and $19.89 \pm 1.51 \mathrm{nM}$ for K1) and better than those of chloroquine $(26.20 \pm 3.66 \mathrm{nM}$ for 3D7 and $740.07 \pm 95.67 \mathrm{nM}$ for K1). Sm exhibited a lower resistance index (2.1) than chloroquine (28.24) against $P$. falciparum K1 [28]. Conversely, Sm exhibited cytotoxicity against HFFs with a $\mathrm{CC}_{50}$ of $1.14 \pm 0.03 \mu \mathrm{M}$, resulting in SIs of 94.45 and 44.83 for 3D7 and K1, respectively. Sm meets the validated hit selection criteria for antimalarial compounds [29], including an $\mathrm{IC}_{50}$ of $<1 \mu \mathrm{M}$ for sensitive and resistant strains of Plasmodium spp., as well as greater than 10-fold selectivity between the $\mathrm{CC}_{50}$ for the mammalian cell line (HFFs in this study) and the $\mathrm{IC}_{50}$ for Plasmodium spp. Regarding cytotoxicity against human erythrocytes, Sm exhibited a low erythrocyte hemolysis rate at $100 \mu \mathrm{M}(1.04 \pm 0.23 \%)$, a concentration that was approximately 5000 -fold higher than the $\mathrm{IC}_{50}$. This hemolysis rate falls with the safe range $(<2 \%)$ recommended by the American Society for Clinical Pathology [30].

In vitro cultures of $P$. falciparum 3D7 exposed to 10 or $50 \mathrm{nM} \mathrm{Sm}$ for 1-72 h were blocked in the ring stage (Figure 2A), indicating that Sm might disrupt the P. falciparum ribosome and possibly its three translationally active subcellular compartments, i.e., cytosol, apicoplasts and mitochondria [31,32]. Similar retained phenotype profiles of P. falciparum 3D7 were observed following treatment with the protein translation inhibitors REP3123 and REP8839 [33]. Translation inhibitors, including azithromycin [34], doxycycline [35] and tetracyclines [36], have also exhibited great clinical success as potent antimalarials. The Plasmodium ribosomes do not fit into the prokaryotic-eukaryotic classification and they appear to be a mixed population of these ribosomes or evolutionary in the middle of 
prokaryotic-eukaryotic ribosomes (70S and 80S) [35]. Accordingly, a therapeutic window has resulted from the distinction between Plasmodium cytoplasmic ribosomes and the human ribosomes.

After $72 \mathrm{~h}$ of exposure to Sm (Figure 3A), cells were incubated for an additional $72 \mathrm{~h}$ in the presence (unwashed group) or absence (washed group) of Sm. Parasite growth remained inhibited with prolonged culture in the unwashed group. Interestingly, in the washed group, the growth of parasites was not restored after the removal of Sm, indicating that the protein synthesis mechanism was damaged by $72 \mathrm{~h}$ of exposure of Sm. These results also demonstrated that $\mathrm{Sm}$ acts as a parasiticidal agent.

To confirm the inhibitory activity of Sm against Plasmodium spp., an in vivo rodent malaria test was performed using P. yoelii 17XNL- and P. berghei ANKA-infected mice. Although Sm is likely inactive when administered orally to mice [7], the reported $\mathrm{LD}_{50}$ of the drug following i.p. administration ranged from 170 to $380 \mu \mathrm{g} / \mathrm{kg}$ per injection in mice and the $\mathrm{IC}_{50}$ in some murine tumor models varied from 125 to $500 \mu \mathrm{g} / \mathrm{kg}$ [22]. Accordingly, in this study, mice were treated with i.p. Sm at a dose of 100 or $300 \mu \mathrm{g} / \mathrm{kg}$ per injection to avoid any toxic effects. In the uncomplicated rodent malaria model using P. yoelii 17XNLinfected mice and a 7-day Sm regimen, no inhibition was observed at a dose of $100 \mu \mathrm{g} / \mathrm{kg}$ (Figure 4A). Meanwhile, partial inhibition of parasite growth was observed in the presence of $300 \mu \mathrm{g} / \mathrm{kg} \mathrm{Sm}(p<0.05$; Figure 4B), in addition to a significantly lower parasitemia peak (18.85\%; $11 \mathrm{dpi})$ than that observed in the control group $(40.13 \% ; 12 \mathrm{dpi})$, without causing mortality. In another set of experiments, the 4- and 7-day Sm regimens prolonged the survival of P. berghei ANKA-infected mice (Figure 5) by $33 \%$ (up to $25 \mathrm{dpi}$ ). The difference between the in vitro and in vivo antiplasmodial activity of Sm possibly resulted from its toxicity and rapid metabolic clearance [37,38], which does not allow adequate drug levels to be reached in vivo. A difference between in vitro and in vivo results was also reported for the antitumor activity of Sm [22].

A

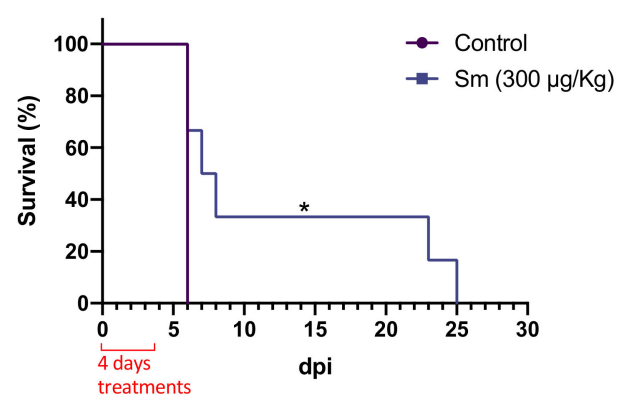

B

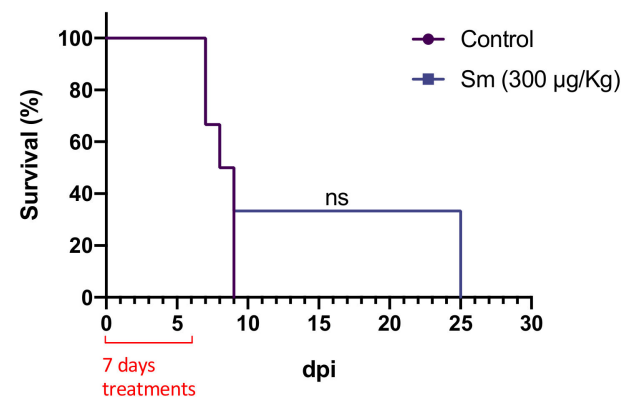

Figure 5. Effects of (A) 4 or (B) 7 days of treatment with $300 \mu \mathrm{g} / \mathrm{kg}$ sparsomycin (Sm) on the survival of C57BL/ 6 mice infected with $P$. berghei ANKA. Mice were infected via inoculation with $1 \times 10^{7}$ infected erythrocytes. Each group consisted of six mice. ${ }^{*}$, significant $(p<0.05)$; ns, not significant $(p>0.05)$. Survival rates were calculated using the log rank (Mantel-Cox) test.

The use of Sm was discontinued from a phase I clinical study because of a finding that, by daily doses of Sm, two out of five patients (with advanced carcinoma) developed ring scotoma after 13 days (total dose of $0.24 \mathrm{mg} / \mathrm{kg}$ ) and 15 days (total dose of $0.15 \mathrm{mg} / \mathrm{kg}$ ); this effect was later defined as Sm-related retinopathy [12]. Later identification by Ottenheijm et al. [7] reported no observable pathological changes in the retinas of any animal treated with toxic doses of Sm and further suggested that Sm-related retinopathy was caused by a poor general condition of the patients and inappropriate drug schedules. By these facts, the chance to use Sm as an alternative drug in malaria is still open. Considering the in vitro and in vivo effects in this study, further development of an Sm scaffold warrants extensive study to address the cytotoxic effects and maintain, or even increase, the antiplasmodial effectivity. 
In summary, Sm exhibited comparably potent antiplasmodial activity as chloroquine and artemisinin in vitro. However, this study is limited to the inhibitory activity of Sm against the blood stage of Plasmodium spp.; accordingly, investigation in different parasitic stages may give further information/hints to use this compound as an antiplasmodial agent effectively. Furthermore, a more extensive investigation related to the inhibition of three translationally active subcellular compartments of Plasmodium spp. may identify which subcellular compartment was specifically inhibited by Sm. Furthermore, the cytotoxic and partial inhibition of parasite growth in vivo of Sm highlights the need for structure-activity studies of Sm derivatives against malaria infection to achieve a better therapeutic index than the parental compound.

Author Contributions: Conceptualization, C.-i.N. and Y.N.; methodology, N.R.A. and Y.N.; validation, Y.N.; formal analysis, N.R.A. and Y.N.; investigation, N.R.A. and B.P.; resources, C.-i.N.; data curation, N.R.A. and B.P.; writing—original draft preparation, N.R.A.; writing—review and editing, Y.N.; visualization, N.R.A.; supervision, Y.N.; project administration, Y.N.; funding acquisition, C.-i.N. and Y.N. All authors have read and agreed to the published version of the manuscript.

Funding: This study was supported by KAKENHI Grants from the Japan Society for the Promotion of Science (20KK0152 and 20F20402 (Y.N.), 26670204 (C.-i.N.)) and the joint research grants from the NRCPD, Obihiro University of Agriculture and Veterinary Medicine (2020-joint-14, 27-joint-6, 28-joint-3, 29-joint-4 (C.-i.N.)). In addition, N.R.A. is supported by the Japan Society for the Promotion of Science (JSPS) Postdoctoral Fellowship for Overseas Researcher (P20402).

Institutional Review Board Statement: The protocol for malaria parasite culture in human blood was approved by the ethical committee of Obihiro University of Agriculture and Veterinary Medicine (permit number 2013-04-3). The animals used in this study were treated according to the Guide for the Care and Use of Laboratory Animals of the Ministry of Education, Culture, Sports, Science and Technology, Japan. The animal experiment protocols were approved by the Institutional Ethics Committee of the Obihiro University of Agriculture and Veterinary Medicine (permit number 21-35).

Informed Consent Statement: Not applicable.

Data Availability Statement: Not applicable.

Acknowledgments: We are grateful to Kunio Issiki, Kazuro Shiomi and Masayuki Igarashi (Institute of Microbial Chemistry-BIKAKEN) for supporting this study. In addition, we thank Ahmed Abdou (NRCPD) for his support in animal experiments. We also thank the Japanese Red Cross Society, Hokkaido, for supplying the human RBCs. Finally, we thank Joe Barber, from Edanz (https://jp.edanz.com/ac, accessed on 28 February 2022) for editing a draft of this manuscript.

Conflicts of Interest: The authors declare no conflict of interest.

\section{References}

1. Wang, G.-H.; Gamez, S.; Raban, R.R.; Marshall, J.M.; Alphey, L.; Li, M.; Rasgon, J.L.; Akbari, O.S. Combating Mosquito-Borne Diseases Using Genetic Control Technologies. Nat. Commun. 2021, 12, 4388. [CrossRef]

2. World Health Organization. World Malaria Report 2021; World Health Organization: Geneva, Switzerland, 2021.

3. World Health Organization. Malaria Eradication: Benefits, Future Scenarios and Feasibility. A Report of the Strategic Advisory Group on Malaria Eradication; World Health Organization: Geneva, Switzerland, 2019; ISBN 9789240003675.

4. Talisuna, A.O.; Bloland, P.; D'Alessandro, U. History, Dynamics, and Public Health Importance of Malaria Parasite Resistance. Clin. Microbiol. Rev. 2004, 17, 235-254. [CrossRef]

5. Ross, L.S.; Fidock, D.A. Elucidating Mechanisms of Drug-Resistant Plasmodium falciparum. Cell Host Microbe 2019, 26 , 35-47. [CrossRef]

6. Argoudelis, A.D.; Herr, R.R. Sparsomycin, a New Antitumor Antibiotic. II. Isolation and Characterization. Antimicrob. Agents Chemother. 1962, 780-786.

7. Ottenheijm, H.C.J.; Van Den Broek, L.A.G.M.; Ballesta, J.P.G.; Zylicz, Z. 6 Chemical and biological aspects of sparsomycin, an antibiotic, from streptomyces. In Progress in Medicinal Chemistry; Elsevier: Amsterdam, The Netherlands, 1986; Volume 23, pp. 219-268.

8. Porse, B.T.; Kirillov, S.V.; Awayez, M.J.; Ottenheijm, H.C.J.; Garrett, R.A. Direct Crosslinking of the Antitumor Antibiotic Sparsomycin, and Its Derivatives, to A2602 in the Peptidyl Transferase Center of 23S-like RRNA within Ribosome-TRNA Complexes. Proc. Natl. Acad. Sci. USA 1999, 96, 9003-9008. [CrossRef] 
9. Hansen, J.L.; Moore, P.B.; Steitz, T.A. Structures of Five Antibiotics Bound at the Peptidyl Transferase Center of the Large Ribosomal Subunit. J. Mol. Biol. 2003, 330, 1061-1075. [CrossRef]

10. Nelli, M.R.; Heitmeier, K.N.; Looper, R.E. Dissecting the Nucleoside Antibiotics as Universal Translation Inhibitors. Acc. Chem. Res. 2021, 54, 2798-2811. [CrossRef]

11. Burgers, L.D.; Fürst, R. Natural Products as Drugs and Tools for Influencing Core Processes of Eukaryotic MRNA Translation. Pharmacol. Res. 2021, 170, 105535. [CrossRef] [PubMed]

12. Mcfarlane, J.R.; Yanoff, M.; Scheie, H.G. Toxic Retinopathy Following Sparsomycin Therapy. Arch. Ophthalmol. 1966, 76, 532-540. [CrossRef] [PubMed]

13. Schmeing, T.M.; Huang, K.S.; Kitchen, D.E.; Strobel, S.A.; Steitz, T.A. Structural Insights into the Roles of Water and the $2^{\prime}$ Hydroxyl of the P Site TRNA in the Peptidyl Transferase Reaction. Mol. Cell 2005, 20, 437-448. [CrossRef] [PubMed]

14. Bashan, A.; Agmon, I.; Zarivach, R.; Schluenzen, F.; Harms, J.; Berisio, R.; Bartels, H.; Franceschi, F.; Auerbach, T.; Hansen, H.A.S.; et al. Structural Basis of the Ribosomal Machinery for Peptide Bond Formation, Translocation, and Nascent Chain Progression. Mol. Cell 2003, 11, 91-102. [CrossRef]

15. Prugnolle, F.; Durand, P.; Ollomo, B.; Duval, L.; Ariey, F.; Arnathau, C.; Gonzalez, J.P.; Leroy, E.; Renaud, F. A Fresh Look at the Origin of Plasmodium falciparum, the Most Malignant Malaria Agent. PLoS Pathog. 2011, 7, e1001283. [CrossRef]

16. Ding, X.C.; Ubben, D.; Wells, T.N. A Framework for Assessing the Risk of Resistance for Anti-Malarials in Development. Malar. J. 2012, 11, 1-11. [CrossRef]

17. Chauhan, R.; Awasthi, V.; Thakur, R.S.; Pande, V.; Chattopadhyay, D.; Das, J. CD4+ICOS+Foxp3+: A Sub-Population of Regulatory T Cells Contribute to Malaria Pathogenesis. Malar. J. 2022, 21, 1-10. [CrossRef]

18. Leesombun, A.; Iijima, M.; Pagmadulam, B.; Orkhon, B.; Doi, H.; Issiki, K.; Sawa, R.; Nihei, C.-i.; Nishikawa, Y. Metacytofilin Has Potent Anti-Malarial Activity. Parasitol. Int. 2021, 81, 102267. [CrossRef]

19. Smilkstein, M.; Sriwilaijaroen, N.; Kelly, J.X.; Wilairat, P.; Riscoe, M. Simple and Inexpensive Fluorescence-Based Technique for High-Throughput Antimalarial Drug Screening. Antimicrob. Agents Chemother. 2004, 48, 1803-1806. [CrossRef]

20. Le Manach, C.; Scheurer, C.; Sax, S.; Schleiferböck, S.; Cabrera, D.G.; Younis, Y.; Paquet, T.; Street, L.; Smith, P.; Ding, X.C.; et al. Fast in Vitro Methods to Determine the Speed of Action and the Stage-Specificity of Anti-Malarials in Plasmodium falciparum. Malar. J. 2013, 12, 1-7. [CrossRef]

21. Evans, B.C.; Nelson, C.E.; Yu, S.S.; Beavers, K.R.; Kim, A.J.; Li, H.; Nelson, H.M.; Giorgio, T.D.; Duvall, C.L. Ex Vivo Red Blood Cell Hemolysis Assay for the Evaluation of PH-Responsive Endosomolytic Agents for Cytosolic Delivery of Biomacromolecular Drugs. J. Vis. Exp. 2013, 73, e50166. [CrossRef]

22. Zylicz, Z.; Wagener, D.J.T.; van Rennes, H.; van der Kleijn, E.; Lelieveld, P.; van den Broek, L.A.G.M.; Ottenheijm, H.C.J. In Vivo Antitumor Activity of Sparsomycin and Its Analogues in Eight Murine Tumor Models. Invest. New Drugs 1988, 6, $285-292$. [CrossRef]

23. Chen, M.; Theander, T.G.; Christensen, S.B.; Hviid, L.; Zhai, L.; Kharazmi, A. Licochalcone A, a New Antimalarial Agent, Inhibits in Vitro Growth of the Human Malaria Parasite Plasmodium falciparum and Protects Mice from P. yoelii Infection. Antimicrob. Agents Chemother. 1994, 38, 1470-1475. [CrossRef]

24. Peters, W.; Portus, J.H.; Robinson, B.L. The Chemotherapy of Rodent Malaria, XXII: The Value of Drug-Resistant Strains of $P$. berghei in Screening for Blood Schizontocidal Activity. Ann. Trop. Med. Parasitol. 1975, 69, 155-171. [CrossRef]

25. Fredrick, K.; Noller, H.F. Catalysis of Ribosomal Translocation by Sparsomycin. Science 2003, 300, 1159-1162. [CrossRef]

26. Prokhorova, I.V.; Akulich, K.A.; Makeeva, D.S.; Osterman, I.A.; Skvortsov, D.A.; Sergiev, P.V.; Dontsova, O.A.; Yusupova, G.; Yusupov, M.M.; Dmitriev, S.E. Amicoumacin A Induces Cancer Cell Death by Targeting the Eukaryotic Ribosome. Sci. Rep. 2016, 6, 27720. [CrossRef] [PubMed]

27. Gilles, A.; Frechin, L.; Natchiar, K.; Biondani, G.; von Loeffelholz, O.; Holvec, S.; Malaval, J.L.; Winum, J.Y.; Klaholz, B.P.; Peyron, J.F. Targeting the Human 80S Ribosome in Cancer: From Structure to Function and Drug Design for Innovative Adjuvant Therapeutic Strategies. Cells 2020, 9, 629. [CrossRef]

28. Tong, J.X.; Chandramohanadas, R.; Shyong-Wei Tan, K. High-Content Screening of the Medicines for Malaria Venture Pathogen Box for Plasmodium falciparum Digestive Vacuole-Disrupting Molecules Reveals Valuable Starting Points for Drug Discovery. Antimicrob. Agents Chemother. 2018, 62, e02031-17. [CrossRef] [PubMed]

29. Katsuno, K.; Burrows, J.N.; Duncan, K.; Van Huijsduijnen, R.H.; Kaneko, T.; Kita, K.; Mowbray, C.E.; Schmatz, D.; Warner, P.; Slingsby, B.T. Hit and Lead Criteria in Drug Discovery for Infectious Diseases of the Developing World. Nat. Rev. Drug Discov. 2015, 14, 751-758. [CrossRef] [PubMed]

30. Goyal, T.; Schmotzer, C.L. Validation of Hemolysis Index Thresholds Optimizes Detection of Clinically Significant Hemolysis. Am. J. Clin. Pathol. 2015, 143, 579-583. [CrossRef]

31. Sheridan, C.M.; Garcia, V.E.; Ahyong, V.; DeRisi, J.L. The Plasmodium Falciparum Cytoplasmic Translation Apparatus: A Promising Therapeutic Target Not yet Exploited by Clinically Approved Anti-Malarials. Malar. J. 2018, 17, 1-13. [CrossRef] [PubMed]

32. Jackson, K.E.; Habib, S.; Frugier, M.; Hoen, R.; Khan, S.; Pham, J.S.; de Pouplana, L.R.; Royo, M.; Santos, M.A.S.; Sharma, A.; et al. Protein Translation in Plasmodium Parasites. Trends Parasitol. 2011, 27, 467-476. [CrossRef]

33. Hussain, T.; Yogavel, M.; Sharma, A. Inhibition of Protein Synthesis and Malaria Parasite Development by Drug Targeting of Methionyl-TRNA Synthetases. Antimicrob. Agents Chemother. 2015, 59, 1856-1867. [CrossRef] 
34. Rosenthal, P.J. Azithromycin for Malaria? Am. J. Trop. Med. Hyg. 2016, 95, 2-4. [CrossRef]

35. Budimulja, A.S.; Syafruddin; Tapchaisri, P.; Wilairat, P.; Marzuki, S. The Sensitivity of Plasmodium Protein Synthesis to Prokaryotic Ribosomal Inhibitors. Mol. Biochem. Parasitol. 1997, 84, 137-141. [CrossRef]

36. Dahl, E.L.; Shock, J.L.; Shenai, B.R.; Gut, J.; DeRisi, J.L.; Rosenthal, P.J. Tetracyclines Specifically Target the Apicoplast of the Malaria Parasite Plasmodium falciparum. Antimicrob. Agents Chemother. 2006, 50, 3124-3131. [CrossRef]

37. Zylicz, Z.; Theo Wagener, D.J.; del Moral, P.F.; van Rennes, H.; Wessels, J.M.C.; Winograd, B.; van der Kleijn, E.; Vree, T.B.; van Haelst, U.; van den Broek, L.A.G.M.; et al. Pharmacokinetics and Toxicology of Sparsomycin in Beagle Dogs. Cancer Chemother. Pharmacol. 1987, 20, 115-124. [CrossRef]

38. Zylicz, Z. Sparsomycin and Its Analouges: A Preclinical Study on Novel Anticancer Drugs; University Hospital Nijmegen: Nijmegen, The Netherlands, 1988. 